\title{
What kind of an urban future is there for the Alps?
}

\author{
C. Diamantini \\ Department of Civil, Environmental and Mechanical Engineering, \\ University of Trento, Italy
}

\begin{abstract}
Faced with processes able to radically modify the evolutional conditions of the Alpine space, such as the rapid transformations induced by global change, the acceleration of a dominance-dependence relationship between the plains and the mountains and the decline in population in many mountainous areas, several authors have proposed an autonomous and self-centred development for the Alps, in which the essential focus lies on transforming a mountain into a city. A distinct city, however, compared to those created by the homologating processes of contemporary urbanization.

With reference to this new urbanity some authors have spoken of "sweet metropolisation" attributing to the latter two fundamental characteristics: the external integration in supra-regional networks and the internal integration between city and its hinterlands. But while on the functional aspects of this double integration there is a significant agreement, i.e. cities should compete to acquire advanced functions while continuing to interact with their hinterlands, some ambiguity remains on the "form" of this metropolisation. For consideration, should the mountain transform itself into a city or should the city transform itself into the mountain, meaning that the city should take charge of the environmental processes in a sustainability perspective?
\end{abstract}

Keywords: Alpine space, Alpine cities, new urbanity, peri-urban agriculture.

\section{Introduction}

For some time now, there have been processes underway in the Alpine area which are radically modifying its evolution. These involve above all the rapid transformations introduced by globalisation which tends to relegate the Alpine 
area, once divested of its own identity, to the rank of "global entertainment district"; an acceleration in the dominance-dependence relationship between metropolises on the plains and the mountain considered as a space subject to development choices directed from outside and, finally, the population drain affecting many alpine areas, driven by the force of attraction exerted by the perialpine urban agglomerations as a result of the services they offer.

Faced with these processes, many authors consider that the mountain should have an urban future, meaning that the alpine area should first and foremost reinforce its urban system, starting with redefinition of the role of the most important urban centres [1-3]. This reinforcement would, in fact, allow the alpine area to pursue autonomous local-centred development and consequently to acquire greater negotiating power in relation to those exerting the greatest pressure on the Alps, particularly metropolises on the plains.

To this end, the most important alpine urban centres should interact actively with the super-regional networks, while guaranteeing continuity of the urban-rural relationships. In other words, it would no longer be sufficient for these centres to take on the role of mediator between super-local functions and the local area. They should instead be directly responsible for those super-local functions, otherwise they risk marginalisation and direct control of the resources and space of the mountain by external parties.

In some ways and in some alpine areas, transformation of the mountain into city has already begun $[2,4]$. At this point, another problem is raised. There is, in fact, a risk that by acquiring advanced functions, and therefore becoming something else from what it is today, the alpine city could lose its specific characteristics and with them, its relative competitive advantages. Some authors maintain that it is a matter of associating the mountain-to-city transformation process with the objective of keeping the mountain agglomerations distinct from the perialpine agglomerations and plain metropolises, by proceeding in such a way that the alpine city reflects the specific natural, historical, cultural, cognitive and institutional characteristics of the area of which it is a part [2].

This paper takes up these themes, first reporting a number of cases in which transformation of the alpine area into a city appears to be underway; then examining the theme of the new alpine urbanity starting from the actual urbanisation process occurring in the Alps, and finally, relating the theme of the construction of the new urbanity to a specific case study involving the area extending to the north of Trento, which re-proposes the node of relationships between city and countryside through a local planning scheme involving the author.

\section{An urban future for the Alpine space: a process already underway}

As it is widely known, the Alpine region is extremely articulated, both in terms of spatial organisation and social and economic conditions and this is also true for relatively homogeneous territories $[2,4]$. 
It can however be said, without risking excessive generalisations, that the mountain-to-city transformation is already having significant evidences. There are, in fact, a number of Alpine cities such as Innsbruck, Trento and others, which appear able to perform advanced functions and therefore play an important role in European-wide urban competition [2]. And, again, dynamic places which, although unable to count on the presence of a large urban centre, nevertheless manage to perform as a city by activating precious synergies.

After a phase during which its economic activities depended essentially on the exploitation of natural resources, Innsbruck managed to initiate a development process based on the creation of high added value service activities, together with the presence of an internationally important university including hospital clinics [4]. In turn, Trento in the space of a few decades established a competitive university, constantly at the top of national Italian classifications for research quality and internationalisation, together with important research centres such as the Bruno Kessler Foundation, the Edmund Mach Foundation and the CoSBi Centre set up on the basis of an agreement between Trento University and Microsoft Research and cultural institutions such as MUSE in Trento and MART in Rovereto.

It is therefore no chance that these two cities, together with Bolzano, are seeking to generate indispensable synergies involving university education and scientific research as a response to instances of the Tyrol-South Tyrol-Trentino Euroregion.

A fundamental role in this evolution has without doubt been played by the political autonomy of the local institutions to which these cities belong, (the Autonomous Province of Trento and Land Tyrol), enabling them to take independent development initiatives and to play an active role on the super-national scene [5].

Something new is also happening in the regions most affected by the economic growth processes. Here, the aspiration to be city goes beyond the limit imposed by the reduced size of the settlements and the absence of a large urban centre with which to establish relationships. In the case of the Vorarlberg Rhine Valley, a tertiary-industrial region of Austria, 29 scattered and spread out individual municipalities and small towns have created a single regional urban space stretching from Bregenz to Feldkirch, used intensively by its inhabitants to live, work and access advanced services beyond community borders.

Similarly, in Switzerland, many urban functions can be found throughout the mountains, weakening the image of the mountains exclusively associated with the skiing industry. As Pia [7] emphasises, we are therefore witnessing the transition from a leisure city exported to the mountains to a city which adopts the mountain as its specific context, just as in the previous case, transforming the mountain into a single large urban space which, in common with sprawling plain cities, uses multiple centralities. 


\section{An urbanisation process that diverges from the future vision of Alpine space}

The distinctive characteristics usually associated with the alpine city may appear in some ways tautological, as they consist in the fact that this city is located in the Alps [8]. The mountain defines both its stage and its horizon, becoming the point of reference in an uninterrupted dialogue between local societies and nature. The interpenetration between city and mountain alone thus ends up by being an element of distinction for alpine cities, which differ from other cities for their unique mixture of anthropic and natural elements.

The alpine city is thus what it is, in the sense that it constantly projects the image of a city, which cannot pull up its roots as those roots go down into an immovable natural setting. This brings comparative advantages deriving from the geographic position, natural resources, fascination of the environment and landscape and the close proximity of the settlement to vast natural spaces, as well as from the presence of open communities living in a multiethnic space. In other words, these are places for living, able to exert a strong attraction towards the outside [1].

These descriptions conjure up the ideal of city proposed at the beginning of last century by Howard [9] in Garden Cities of To-Morrow, achievable through a perfect synthesis (the garden city) between the qualities innate in life in the city and those ones innate in life in the country.

I say this, not because I am not in agreement with the type of image proposed for alpine cities, but to emphasise the visionary character of an image which merges with something desirable but which must be constructed from scratch. This is, moreover, what a number of authors maintain when they emphasise the fact that this new urbanity, which is compared to a utopia, still has to find concrete ways to materialise [10] and that it can only be achieved by taking on a challenge on a number of fronts [2].

On the physical space organisation front, there is no doubt that the alpine region is today both the scene of bitter confrontation between a process of standardisation dictated by changed development models and new lifestyles and attention focussed on maintaining the distinctive traits of the physical structure of the places, including cities, not just in consideration of the consequent comparative advantages, but also because of the cultural values they express. It seems, in fact, ever more evident that the distinguishing characteristic of alpine settlements can today no longer be the simple fact of standing at the feet of the mountains which have always dictated their forms and their horizons.

Alpine communities must act responsibly to ensure that the process leading to standardisation of the physical space is not ascribed generically to the often unintelligible agents of globalisation, but rather to these same communities which in many situations appear to be the only entities responsible for organising land use in their area. In other words, the inhabitants of the mountain themselves can dictate the outcomes of this confrontation.

The starting conditions for beginning to construct a new alpine urbanity appear problematical. As various authors insist, the urbanisation process that has occurred 
in the Alps is not at all unlike that occurring on the plains [1]. During the initial phase, this can be attributed to centralisation of activities and the population in the urban centres, a process occurring spatially outside the historic city centres and generating anonymous suburbs, closely resembling each other; this was followed by decentralisation with a shift of urban activities and part of the population of city-dwellers to small suburban centres and agricultural areas, without any criterion other than that of saving on the cost of the land; then finally the projection of urban functions over a vast area in which the processes ascribable to a number of cities overlap. Only that all this, in many ways sharing the characteristics of urban sprawl, took place in the alpine valley floors, in other words, in a space much smaller than that available for the processes occurring on the plain and already utilised by the passage of important communication axes. The building process thus ended up by saturating the urban basins and valley corridors nearest the cities, with formal results, which were often debatable, even though the fruit of planning schemes.

This latter aspect is of considerable importance. The urbanisation process briefly described above occurred mainly from the 1960s onwards and also made use of urban planning schemes. Only that with a few rare exceptions, these urban planning schemes re-proposed the same solutions for the alpine cities as already adopted for cities on the plains, without taking any account of their specific characteristics. And that even in countries such as Switzerland, which are identified in the collective imagination, with the mountain [11].

The planning schemes therefore, at municipal level aimed principally at creating suitable building space for economic activities and residential purposes, progressively eroding the surrounding farmland, or treating it as areas held in reserve for future construction, without a precise idea based on a desirable urban form. At regional level, they focussed above all on attributing a specific function to those parts of the territory with high environmental value, reserving them in part for economic activities, i.e. tourism, and in part for protection through the creation of natural parks. Always taking care to avoid standing in the way of the cities whose every dynamic had, in any case, to be indulged.

From this point of view, there was a mere application of the zoning criteria with which, often arbitrarily, the various functions on the territory were divided, with a clear separation between remarkable ecosystems and ordinary nature [12]. As is now evident, the result was the separation of the city from its natural hinterland and the progressive loss of the distinctive characteristics of alpine urbanity.

This is reflected both in the fact that today the structure and aspect of alpine cities do not appear different from those of cities away from the Alps (with the result that on the valley floors, it is therefore difficult to distinguish the offshoot of a city from a developed agriculture area) and in the multiplication of conflicts over land use, in particular, between building development and the continuation of farming practices, revealing the progressive disappearance among the inhabitants of a common awareness of the tasks facing them, as well as the common interests to defend. 


\section{What new urbanity?}

What could represent the basis for a different organisation of the places (and urban landscape) and be associable with a new urbanity? The theme is obviously of a more general nature than that raised by cities in the Alps and during the last two decades has received various different responses, partly stimulated by the paradigm of sustainable development. In a certain sense, these converge on the need to restore non-conflictual relationships between urban and natural processes, starting with recognition of the functions and services performed by ecosystems. In this context, agriculture has become particularly important, both as an ecosystem, although under considerable anthropic pressure, and as a constituent element of the landscape [13-17].

Certain authors, starting with Donadieu [18] have identified agriculture (or rather, the urban countryside) as the pivot around which to make the new urban-rural relationships revolve, while in turn architects and planners have started a densely packed phase of experiences aimed at developing a landscape capable of giving coherence to places [19]. These approaches can without doubt be transferred to cities in the Alps, with the necessary remarks.

It must first be said that the picture offered by the alpine cities is in many ways less compromised than that offered by cities on the plain, where peri-urban agriculture is usually relegated to residual space or gaps and practised as a supplementary, or even free time, activity. The recurrent design themes in plain cities therefore range from composition of a mosaic within which to create small pieces of ecosystems in the place of abandoned land, to the integration into the urban space of fragments of farmland otherwise destined for building development.

Near a number of alpine cities on the other hand, it is still possible to recognise a type of farming, which is far from being residual, or occupying residual spaces. Over the last two or three decades, this agriculture has become ever more specialised, to the point where it produces products of excellence. Often this agriculture is accompanied by tourism activities in the form of farm holidays and the profit resulting from this significantly supplements that coming from agriculture.

A number of factors contribute to the continuity of this agriculture, which even near the cities still makes a distinctive contribution to defining the landscape of the alpine valley floors, together with the high mountains and extensive forested areas. These include:

- $\quad$ The limited size of alpine cities with respect to those on the plains;

- The less invasive forms of suburbanisation, by virtue of the size of the original city and the relatively "light" nature of the decentralised urban functions;

- The morphology of the places which on one hand has contributed to amplifying the effects of even limited processes, and on the other, has prevented massive urbanisation, particularly on the high ground;

- The importance of the agricultural areas on the alpine valley floors, 
including in terms of the ecosystem services they provide [20];

- The frequent presence of environmental high-risk areas, for which agricultural use is the only possible alternative.

Secondly, the crisis underway for some time in the less competitive manufacturing system, leading to the abandonment of significant production sites and likely to continue in the future, also favours peri-urban farming near cities in the Alps. In the same way, part of the more obsolete national and international systems associated with commerce have also been affected by the crisis, in turn leading to the abandonment of extensive areas previously used for goods handling. Together with the more general context of economic crisis, this has resulted on one hand, in a significant slowing down in building development and on the other, in an opportunity to recycle the abandoned land, in a situation characterised by the scarce availability of space suitable for urban activities. This recycling can, if not actually restore directly agricultural use of the areas, at least prepare spaces and containers for agricultural and food production, or for services associated with the agricultural production chain.

Thirdly, the peri-urban farming associated with alpine cities is often based on important networks of actors who, during the last few decades, have organised strong opposition to the transformation of agricultural land, reinforced during recent years precisely as a result of the growing solidity and importance of agricultural practices.

The presence of these networks and the effectiveness of their actions acquire ever more decisive weight as they are gradually transformed into forms of organisation able to play a decisive role in fundamental policy decision-making [21]. For example, it is well known that land-use policies in the South Tyrol and the substantial defence of agricultural land around the city of Bolzano in particular, can be attributed to the strong influence played by the Südtiroler Bauernbund (the South Tyrolean small farmers association) on the Südtiroler Volkspartei (the party representing the German-speaking population) which has led the Autonomous Province of Bolzano for the last decades [22].

The fact that alpine peri-urban agriculture can count on important actors implies the possibility of overturning the prospects with respect to what happens (or it is hoped happens) in cities on the plains. In the latter, agriculture cannot play anything but a passive role as its continuity is at the mercy of discretionary urban choices which may or may not be implemented, according to the moods of the city. In the Alps, on the other hand, the continuity of farming practices is based on a widespread awareness of the value of agriculture, attributable not just to the products, but also to the lifestyle it expresses and the formal values (landscape first and foremost) with which it is associated.

In alpine peri-urban areas, it is thus possible to establish a dialogue between subjects of equal dignity, although expressing different realities - the city and the countryside - in which these can find a common interest in the construction of new urban-rural relationships and thus a new urbanity. 


\section{A testing ground: the Rotaliana-Königsberg territory}

The Rotaliana-Königsberg territory (fig. 1) extends along the section of the Adige Valley, which begins immediately to the north of Trento and ends at the border between Trentino and South Tyrol.

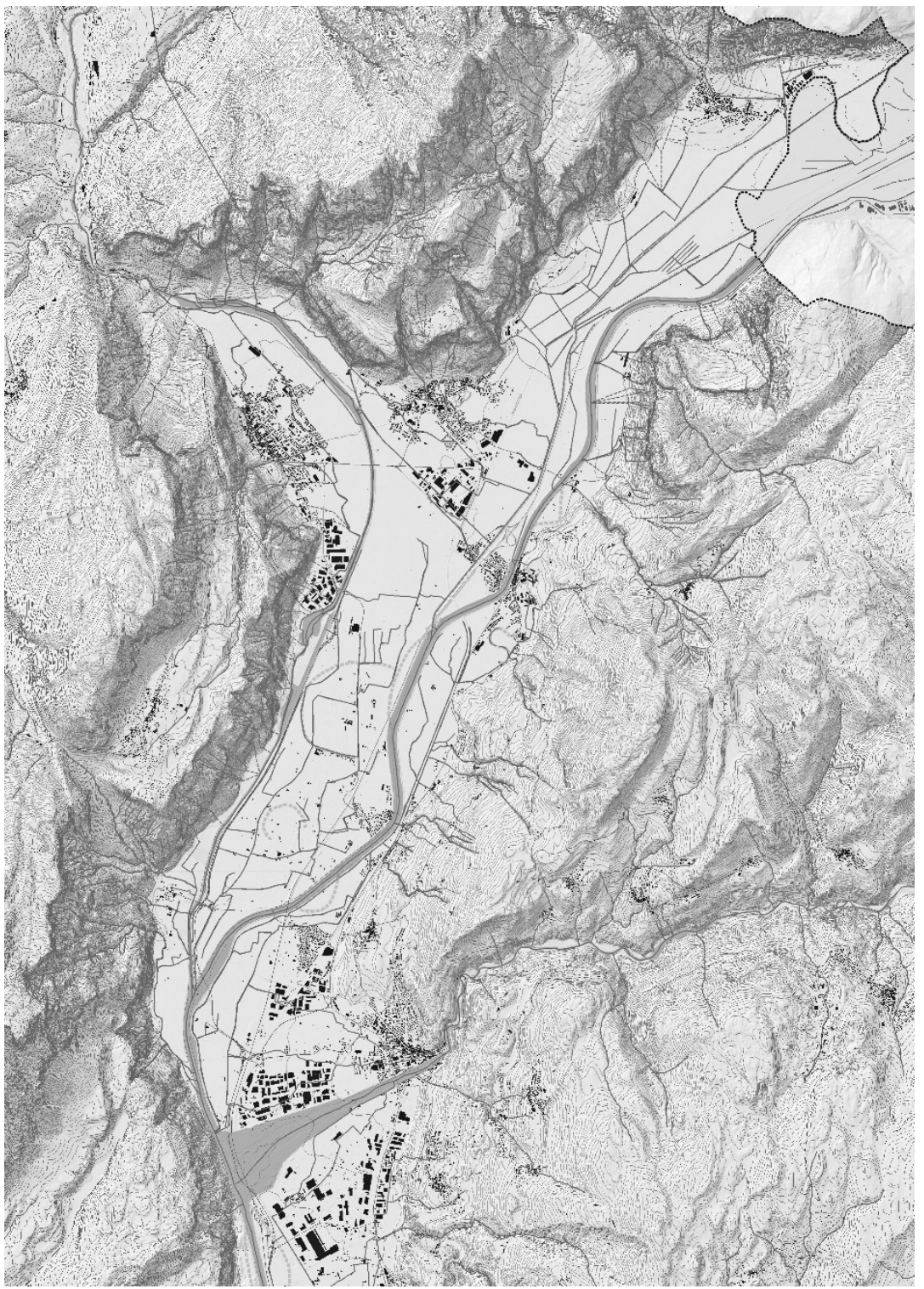

Figure 1: The Rotaliana-Königsberg territory. Down below, the industrial area of Trento. 
During the 1960s this area still had the characteristics, which had distinguished it for centuries, with the exception of utilisation of the valley floor made possible by hydraulic regulation of the river dating from the mid-19th century. The settlements followed the traditional Alpine valley floor pattern with small towns and villages built on the alluvial fans or less steep slopes of the valley sides to protect them from floods and the valley floor entirely occupied by farmland. The only crisis factor for this system was the presence of a pollutant industrial factory in the valley floors, justified only by the distance from the city.

The city did not begin to exert pressure until the 1970s, following approval of the Autonomous Province of Trento's first land use plan in 1967. The plan, in fact, envisaged creation of three big industrial zones in the Rotaliana-Königsberg area, including one in continuity with the industrial zone to the north of Trento on the alluvial fan of the Avisio river and the other two on the Rotaliana Plain which, thanks to the particular composition of the soil and south facing exposure, has always had a particular vocation for wine production. This choice was motivated on one hand, by a conception of development which gave industry a driving role in the economy and on the other, by the presence on the plain of an access to the Brennero motorway (then under construction).

In subsequent decades, the city exerted pressure through transfer of the place of residence, particularly of the low-income population, and the creation of areas for small industry and commerce, which invaded the agricultural land nearest the city. Together with construction of industrial zones, this pressure, partly due to the settlement processes and building types adopted, gave the Rotaliana-Königsberg valley floor an indistinct character, particularly near the city, with a disorderly mix of mediocre urban areas and anonymous rural spaces.

There are still, however, extensive areas of the valley floor covered with vineyards and orchards, together with the entire hill on the orographic left of the Adige River, much of whose largely vineyard-covered terraces has been spared by the urban sprawl.

The relative integrity of these agricultural areas is due only in small measure to the attention paid to them by urban planning schemes, as three different types of actor have played a decisive role. The first is represented by local operators organised into cooperatives set up mostly in the mid-1900s for the production and sale of agricultural products. These operators are active above all on the valley floor where they maintain a presence on those areas of the Rotaliana Plain spared by urbanisation. A successful presence considering that they have imposed their brand, which takes its name from a local grape, at the international level. The second category of actor includes wine companies and wine makers, two categories which differ for quantity of product which the former obtains also using grapes from third parties.

Both categories include the heirs of peasant farming families, often with a high level of education, and other figures such as professionals who have decided to change their lifestyle. In both cases, these figures have entered the world of wine, bringing with them new managerial techniques, important innovations and new energy. Both the wine companies and wine makers, in particular those whose land was in closest contact with the urban growth processes, have managed to 
successfully oppose both the temptations of easy profits to be earned by selling off their property and attempts at expropriating their land, managing in recent years to consolidate a reality which now boasts solid economic roots.

The new Science Museum in Trento includes an exhibition created on the initiative of a wine company and recounting this reality better than all the detailed descriptions. It is entitled Wine \& Soil and the aim is to communicate the connection existing between the varieties of grape grown in the RotalianaKönigsberg area and the particular litho types that can be found in soils where they are cultivated. But in fact, another message emerges, namely the assertion of both a deep link between wine production and this land and a sense of territoriality and belonging.

For a certain period, this persistence of local actors and agricultural land which did not belong to the city, but at the same time no longer belonged to the rural world represented a necessary, but not sufficient, precondition for redefining relationships between the urban and the rural. It certainly contributed to defending, although only partially, the character of the places, but in the absence of a long-term plan, which could emerge only through a pact based on the equal dignity of the contracting parties and to be entered into first and foremost with the city.

A unique opportunity in this context is represented by the recent attribution of relative autonomy to Rotaliana-Königsberg (previously denied by inclusion of a city in the area), including with reference to the designated land use. By starting to draw up a land-use plan, the community has already begun building its own future image, completely separate from that of urban periphery and based, on the contrary, on its agricultural vocation and, together with that, a sort of otherness with respect to the city.

This image is not one of closure towards the city (and it could hardly be otherwise, given that a considerable proportion of the population depends on the city for jobs and access to services), but one which invites a parallel re-examination and, above all, organisation of the places in which the subjects, city and peri-urban countryside, can recognise each other, thus laying the foundations for constructing a new urbanity. The result is an articulation of the planning project on three strictly inter-related levels.

The first level consists of all the actions aimed at creating the image of an area with an agricultural vocation, including downgrading of the two industrial areas which, once re-dimensioned, would accommodate production, commercial and service activities associated with the agricultural, food and timber production chains.

The second level includes all the actions aimed at "slowing down" utilisation of the area, including by the city, with routes and systems for accessing the various agricultural products (alongside wine and apples, high quality horticultural production has also been developed), characterised by slow speed mobility.

The third level is represented by all the actions aimed on the one hand at improving landscapes quality and, on the other, at utilising the agricultural ecosystems also from an ecological point of view, paying particular attention to utilisation of the dense network of canals and ditches (today utilised exclusively for irrigation) as ecological corridors. 
Finally, the fourth level involves point interventions on the initiative of the population or local administrations, including an energy production system using various renewable energy sources, starting with waste from wine production.

\section{Conclusions}

As is widely known, the theme of the sustainable city has attracted great attention among town planners and ecologists who have set about achieving integration between urban processes and natural processes, refusing to accept that dialogue between the two is impossible [23]. In particular, this has involved stimulating creation of a network of semi-natural spaces within the city, to be connected in turn with open suburban spaces consisting of green belts or farmland. This connection between city and open space generally occurs on the initiative of the cities, both due to their political weight and the marginal character of peri-urban agriculture. Moreover, given the residual character of the urban and peri-urban open spaces, it ends up having more a recreational than an environmental role.

For the mountain undergoing transformation (or which should hopefully be transformed) into city, the prospect of the sustainability of this process and its outcome is an absolute imperative.

If this is not the case, the characterising traits of the alpine city would in fact disappear and it would become completely standardised with plain cities. There are, however, two points of strength supporting the new urbanity which should be the target for alpine cities, on one hand, the relative integrity and landscape value of many urban and peri-urban spaces and on the other, the presence of local actors in rural areas able to dialogue with the city from a position of equality. This makes it credible that while the mountain is becoming city, the city can also become mountain, assuming direct responsibility for safeguarding the environmental processes and quality of the landscape.

\section{References}

[1] Perlik, M., Messerli, P., \& Bätzing, W., Towns in the Alps. Urbanization processes, economic structure and demarcation of European Functional Urban Areas (EFUAs) in the Alps, Mountain Research and Development, 21(3), pp. 243-252, 2001.

[2] Dematteis, G., Polycentric urban regions in the Alpine space, Urban Research and Practice, 2(1), pp. 18-35, 2009.

[3] Nared, J., The development of mountain regions, Regions Magazine, 280 (1), p. 13, 2010.

[4] Perlik, M., Messerli, P., Urban Strategies and Regional Development in the Alps, Mountain Research and Development, 24(3), pp. 215-219, 2004.

[5] Diamantini, C., About mountains becoming cities. Relationships between the city and the hinterland of Trento. Italy. Territories en débat, eds. R. De Marco \& C. Mattiucci, Professional dreamers: Trento, 2014. In press. 
[6] Hämmerle M., 29 municipalities. One living space. Territories en débat, eds. R. De Marco \& C. Mattiucci, Professional dreamers: Trento, 2014. In press.

[7] Pia F., Le project complex comme stratégie de densification des Alpes, Territories en débat, eds. R. De Marco \& C. Mattiucci, Professional dreamers: Trento, 2014. In press.

[8] Fourny-Kober, M. C., Villes des Alps et identité(s), CipraInfo, 72, p. 5, 2004.

[9] Howard, E., Garden Cities of To-Morrow, 1902. Reprinted by Faber and Faber: London, 1946.

[10] Fourny, M. C., La Ville Alpine, Utopie Urbane et Project Politique, Le Globe, 141, pp. 39-55, 2001.

[11] Crivelli, R., Città alpine o città rurali? Il persistere di una ambiguità nella pianificazione del territorio in Svizzera. AISRe, Associazione Italiana di Scienze Regionali, XXXI Conferenza Scientifica Annuale, Aosta, 20-22 September 2010, pp. 1-18, 2010.

[12] Bertrand, N., Vanpeene-Bruhier, S., Periurban landscapes in Mountain Areas, Journal of Alpine Research, 95(4), pp. 69-80, 2007.

[13] Hough, M., Cities and Natural Processes, Routledge: New York, 1995.

[14] Tjallingii S. T., Ecology on the edge: Landscape and ecology between town and country, Landscape and Urban Planning, 48, pp. 103-119, 2000.

[15] Diamantini, C., Planning to integrate Urban and Ecological Processes (Chapter 4.4). Biological Monitoring of Rivers, eds. G. Ziglio, M. Siligardi \& G. Flaim, Wiley: Hoboken, N.J. pp. 419-433, 2006.

[16] Alberti, M., Advances in Urban Ecology. Integrating Humans and Ecological Processes in Urban Ecosystems, Springer: Washington, D. C., 2008.

[17] Palazzo, D., Steiner, F., Urban Ecological Design. A Process for Regenerative Places, Island Press: Washington, D. C., 2012.

[18] Donadieu, P., Campagnes urbaines, Actes Sud: Arles, 1998.

[19] Desvigne, M., Intermediate Natures, Birkhauser: Basel, 2009.

[20] Ferrari, M., Spatial assessment of multiple ecosystem services in an Alpine region, $\mathrm{PhD}$ Thesis, Doctoral School in Environmental Engineering, University of Trento: Trento, 2014.

[21] Bonerandi, E., Landel, P. A., Roux, E., Les espaces intermédiaires, forme hybride: ville en campagne, campagne en ville? Revue de Géographie Alpine, 91(4), pp. 65-77, 2001.

[22] Diamantini, C, Il progetto di società come progetto di territorio: il modello sudtirolese. Le Alpi. Immagini e percorsi di un territorio in trasformazione, a cura di C. Diamantini, B. Zanon, Temi: Trento, pp. 127-149, 1999.

[23] Corrado F., les territoires fragiles dans la ragion alpine: une proposition de lecture entre innovation et marginalité, Revue de Géographie Alpine, 98(3), pp. 2-9, 2010. 